\title{
Analysis of Students' Online Learning Readiness Based on Their Emotional Intelligence Level
}

\author{
Melih Engin \\ Management Information Systems Department, Faculty of Business, Uludağ University, Turkey
}

Copyright $\bigcirc 2017$ by authors, all rights reserved. Authors agree that this article remains permanently open access under the terms of the Creative Commons Attribution License 4.0 International License

\begin{abstract}
The objective of the present study is to determine whether there is a significant relationship between the students' readiness in online learning and their emotional intelligence levels. Correlational research method was used in the study. Online Learning Readiness Scale which was developed by Hung et al. (2010) has been used and Trait Emotional Intelligence Scale - Short Form (TEIS-SF) developed by K. Petrides and Furnham $(2000,2001)$ were used as data collection tools. The questionnaires were applied to 95 students who attend Computer II course, which is provided only through distance learning in Uludağ University. The conducted analyses demonstrated that there was a meaningful relationship between students' online learning readiness and the individual's emotional intelligence dimension. Individuals with a high social skills sub-dimension of emotional intelligence had high online learning readiness levels. Furthermore, it was determined that self-control emotional intelligence sub-dimension had a greater prediction power on learner control, one of the online learning readiness levels, when compared to other emotional intelligence sub-dimensions.
\end{abstract}

Keywords Online Learning Readiness, Emotional Intelligence Level, Distance Learning

\section{Introduction}

Readiness, which is extremely important in the education-instruction process, is a significant input for learning- teaching system (Bloom, 1995). Change in behavior of the learner is based on the readiness of the student. Today, both learning and teaching could be conducted in online media as well. These settings are different from the ones where education is conducted face to face for both the students and teachers. The factor of readiness to teach for the teacher and to learn for the learner should not be ignored in this different medium. Thus, readiness for online learning is expressed as time management, self-guidance skill, which is in the nature of online learning, adopting the internal resources of motivation, recognition of personal learning style, and experiences (Smith, Murphy, \& Mahoney, 2003).

For students to benefit from online learning settings, they should possess online readiness. Thus, Borotis and Poulymenakou (2004) defined online readiness as "being mentally and physically ready for certain online learning experience and actions," while it was defined as the capacity to follow up the opportunities that facilitate the use of e-resources such as Internet by Choucri et al. (2003). Previous studies considered online learning readiness from different perspectives. Warner, Christie, and Choy (1998) made a three-way definition of the concept of online learning readiness: (1) The mode of education that students prefer to the face to face education, (2) Efficacies of students to utilize Internet and computer-aided communications for learning, (3) The skill to participate in independent learning.

Hung et al. (2010) developed a Readiness for Online Learning Scale that includes sub-dimensions of "self-directed learning, learner control, motivation, computer/internet self-efficacy towards learning and online communications self-efficacy" by considering that five different sub-dimensions should be taken into account while measuring online learning readiness.

Self-efficacy may be defined as an individual's beliefs and expectations in his/her capability to perform a task (Bandura, Barbaranelli, Caprara, \& Pastorelli, 1996). If the belief an individual has in himself or herself in using computers is computer self-efficacy (Rex \& Roth, 1998), then Internet self-efficacy is defined as the trust Internet users have in them while using Internet. Internet self-efficacy could be different from computer self-efficacy in setting up, maintaining, and using the Internet behavior series (Hung et al., 2010).

Internet self-efficacy could influence the strategies of students in accessing information and could facilitate their use of these strategies in Internet-based learning settings (Tsai \& Tsai, 2003). At least three areas: technology, learning, and social interaction should be considered under the term of internet self-efficacy but while the 
technological aspect of online learning has been preferred research area for researchers, the other two areas has rarely been explored (Shen, Cho, Tsai, \& Marra, 2013).

Knowles (1975), defined self-directed learning as a process that includes the states of understanding the learning needs of individuals, creating learning objectives, defining material resources for learning, selecting and implementing appropriate learning strategies, and using the choices in evaluation of learning output. This conception of self-directed learning focuses on the skills and abilities of a learner to engage in the learning process (Zhoc \& Chen, 2016). In self-directed learning process, learners are active in the process of determination of learning objectives, activities, needs and efficacy levels and they take more responsibility for self-learning $(\mathrm{Oh}$, 2006).

Those who learn in web-based learning media have the opportunity to decide which information to access and how to order the information (Lawless \& Brown, 1997), have more flexibility and more personalized means of learning (Lin \& Hsieh, 2001). They have more control on their learning. Students' directing their self-learning experience and process is expressed as learner control (Shyu \& Brown, 1992). Learner control has some potential threats like; a lack of perception of control, making suboptimal choices and a high cognitive load on learners' processing resources influenced by the amount of choice available (Corbalan, Kester, \& van Merriënboer, 2009).

Significance of motivation in education and on the achievements of the students is a well-known issue. Since the structure of online education programs is substantially self-directed, motivation is an important part of learning process in distant learning process as it is in conventional education (Khan, 2009) and it is a requirement for successful online learning (Lim, 2004).

Online learning requires communications via computer and quality in learning experiences in this media, efficiency in learning activities, student interaction and active participation (de Bruyn, 2004). In a study conducted by Stephenson (2001), it was indicated that online interactive environments improve responsibility, critical analysis and reflection, and social structuring of information in students. Thus, online communications are important in online learning process. Online communications self-efficacy of individuals should be considered in removal of the limitations related to online learning.

An overall consideration of the sub-dimensions of online readiness which are mentioned above demonstrates that they mention behaviours of a learning individual such as self-confidence, self-knowledge, self-control, to communicate and self-expression. It could be considered that for online learning experience and actions, individuals should be mentally ready and this is related to their personality traits. Flood (2004) considers learning as an emotional response of an individual to his or her learning method or class, as well as the learning environment. This exhibits that readiness in online learning might have a relationship with the emotional characteristics of the individuals. At this point, we confront the concept of emotional intelligence as an approach that defines and establishes emotional traits of individuals. Emotional intelligence is a concept that is different from individuals' personality dimensions but completely related to the personality (Ramo, Saris, \& Boyatzis, 2009), and it is considered within the context of personality and evaluated with valid self-assessment inventories that assess a typical behaviour (Bar-On, 1997; Salovey, Mayer, Goldman, Turvey, \& Palfai, 1995). Furthermore, it has been reported that the characteristics of personality such as empathy, stubbornness, social skills and friendliness are considered within the realm of emotional intelligence (Schulte, Ree, \& Carretta, 2004). According to Goleman (1995) emotional intelligence is the ability of one to understand his own feelings, to empathize with others' emotions, and to regulate his feelings to enrich life. Thus, the definitions of emotional intelligence reflect elements such as the ability to manage emotions to be able to express them efficiently and appropriately (Cooper, Sawaf, Ayman, \& Sancar, 2003); emotions becoming common sense and the ability to absorb and explain emotions; management of emotions for emotional growth, and ability to guide (Brackett, Mayer, \& Warner, 2004). Emotional intelligence consists of individual, personal, social competence and skills which help individuals cope successfully with the incoming pressure and demand (Titrek, 2013).

An analysis of approaches related to emotional intelligence would show that there are "trait approaches" and "information processing approaches" that aim to explain emotional intelligence. K. Petrides and Furnham (2000) consider emotional intelligence in two different types of "trait" emotional intelligence and "information processing" emotional intelligence. Furthermore, while accepting emotional intelligence as ability, they considered emotional intelligence as a "trait-personality character trait" due to the powerful relationship of emotional intelligence with the main dimensions of personality. They have named their model as "emotional self- efficacy" and Mayer and Salovey's cognitive ability model as "emotional cognitive ability." According to this emotional intelligence model (personal character trait), the skills related to emotional intelligence are perceived skills, which do not exist in reality, and could be measured based on personal statements (K. Petrides \& Furnham, 2001). According to Salovey et al. (1995), individuals with high Emotional Intelligence (EQ) have advantages over individuals with low EQ in emotion regulation. These advantages are emotional self-awareness, stress management, problem solving, emotion regulation, empathy, and protection against the negative stress that intervenes with the ability of the individual to think clearly (Spence, Oades, \& Caputi, 2004). Individuals with high 
EQ could cope with stress better, and could have wider social networks, and could achieve better grades in academic performance by reducing the negative effects of pressure (K. Petrides, Frederickson, \& Furnham, 2004). High emotional intelligence (high self-efficacy), is expressed as perceiving stress as a struggle and an opportunity instead of perceiving stress as a threat. Individuals with high emotional intelligence have more sufficient coping mechanisms for the situations and instead of perceiving the situation as a threat; they consider it as a development (Mikolajczak \& Luminet, 2008). High trait emotional intelligence helps individuals to select adaptive strategies, reducing negative emotions and exchanging negative emotions with positive ones. Against difficult events and situations, individuals with high EQ demonstrate less psychological symptoms and somatic complaints when compared to individuals with lower EQ (Mikolajczak \& Luminet, 2008). Individual differences in processing traumatic stimulants could explain the differences in adaptation to various stressful conditions. According to Polatcan and Titrek (2014)' research the cognitive, emotional and behavioural variables give a highly significant relation.

Trait Emotional Intelligence Scale (K. Petrides \& Furnham, 2000, 2001), developed to measure trait emotional intelligence, exhibits a four sub-dimension structure, which were identified as "well-being", "Self-control skills", "Emotional skills" and "Social skills." Assessment of these dimensions and their context would demonstrate that wellbeing dimension contains having certain good traits, being generally content with life, being aware of/believing in personal qualifications and strengths, generally believing that all would be fine, and having an optimistic outlook. Self-control skills dimension includes controlling emotions, decision making/changing the decisions, coping with stress, being affected positively or negatively from the deeds done. Emotional skills dimension contains differentiating emotions, displaying emotions to the inner circle, thinking about emotions often, bonding with close acquaintances. Social skills dimension includes coping with people, defending own ground, influencing others' emotions, attitudes in conflict environment, etc.

In fact, the nature of the model proposed by K. Petrides and Furnham (2000) was determined by the type of measurement instead of the theory. "Trait emotional intelligence" deals with the consistencies between the situations within a behavior (expressed with specific behavior or traits such as empathy, optimism, decisiveness), instead of abilities (i.e. determination of emotions, expressing emotions, and defining emotions) that emotional intelligence information processing deals with.

Review of the research studies (which were) conducted to scrutinize readiness in learning demonstrates that readiness would affect several variables. Gunawardena and
Duphorne (2001) stressed that when readiness increased, satisfaction from learning experiences increased as well. Fogerson (2005) found that readiness was a significant prerequisite for self-confidence and satisfaction, and also related to self-direction and age. Davis (2006), in the study conducted on the readiness of distance learning stakeholders, staff and students for online learning, stated that readiness was significant in increasing the achievement of the students, to increase the investment in distance learning budget to a maximum level, and to expand lifelong learning potential. Lau and Shaikh (2012) found in their study that gender, financial aid, ethnicity, and class affected the readiness of students for online learning, however learning style did not. In addition, in a different study, it was observed that unsociable students participated more in online learning environments compared to conventional learning environment (Palloff \& Pratt, 2007). In a study by Demir Kaymak and Horzum (2013), it was concluded that readiness of students for online learning increased the interaction in learning environment or the decrease in readiness caused a decrease in interaction. Wong and Law (2002) developed a practically short EI measure that can be used in leadership and management studies. This scale's dimensions are self-emotional appraisal, others' emotional appraisal, regulation of emotion and use of emotion. This scale is used by Buzdar, Ali, and Tariq (2016), to measure emotional intelligence postulated. However, the scale of K. Petrides and Furnham (2001) was employed/ implemented in the current study as the questions of this scale are considered to be more appropriate for the research dynamics and participants' profiles. This scales' questions are more suitable for our research and work group's profiles. With these in mind, the present study was conducted to determine whether there is a meaningful relationship between the readiness and emotional intelligence levels of the participants. In order to attain this aim and contribute to the relevant literature, the following research questions were tried to be answered;

- Is there a statistically significant relationship between emotional intelligence levels and online learning readiness levels?

- Are the emotional intelligence levels significant predictors of online learning readiness levels?

\section{Method}

In the current study, correlational research method, one of the relational screening models, was utilized. Correlational research method scrutinizes the relationship between two or more variables (Fraenkel \& Wallen, 2004). The mentioned method was selected since the relationship between the variables of emotional intelligence and online learning readiness was investigated in the study.

Section the sample of the study included 95 Uludag University Faculty of Theology Department of Primary 
Education Religious Culture and Moral Knowledge sophomore grade students during the 2014 - 2015 academic year fall semester. The course of Software Packages II that these students attended was instructed online and synchronically in a virtual classroom that the researcher initiated using Uludağ University Institutional Education and Research Activities Governance System (UKEY), a Learning Management System (LMS) application provided by Uludağ University. $51.6 \%$ of the 95 students that took the above mentioned course and participated in the study were males $(\mathrm{n}=49)$, and $48.4 \%$ were females $(n=46)$. Within the context of Software Packages II course, the researcher instructed the use of Microsoft Excel Spreadsheet Software synchronically.

18-item "Online Learning Readiness Scale" developed by Hung et al. (2010) and 20-item "Trait Emotional Intelligence Scale - Short Form" developed by K. Petrides and Furnham $(2000,2001)$ and a questionnaire including personal information form sections developed by the researcher to identify certain information about the students were implemented as data collection tools in the study.

Online Learning Readiness Scale: It was developed by Hung et al. (2010) as a 5-point Likert scale. Turkish validity study was conducted by Yurdugül and Sarikaya (2013) and 5 dimensions of Computer/Internet Self-efficacy, Selfdirected learning, Learner Control, Motivation to Learn, and Online Communication Self-efficacy were identified. Table 1 demonstrates the reliability coefficients for Online Learning Readiness Scale as determined by the analyses of this study.

Table 1. Reliabilities of online learning readiness dimensions

\begin{tabular}{|c|c|}
\hline Scale & Study \\
\hline Computer/Internet Self-efficacy & 0,862 \\
\hline Self-directed Learning & 0,736 \\
\hline Learner Control & 0,659 \\
\hline Motivation to Learn & 0,858 \\
\hline Online Communication Self-efficacy & 0,789 \\
\hline
\end{tabular}

Internal consistency reliability of Online Learning Readiness Scale was calculated with Cronbach alpha coefficient. Alpha values for Computer/ Internet Self-efficacy was .862, for Motivation to Learn was .858, for Self- directed learning was .736, for Online Communication Self-efficacy was .789 and for Learner Control was .659. For the total scale, it was found as .895.Trait Emotional Intelligence Scale - Short Form (TEIS-SF): TEIS-SF developed by K. Petrides and Furnham $(2000,2001)$ based on their conceptualization of emotional intelligence as "personality trait," is a scale developed to determine the self-perception level of an individual about her or his emotional efficacies. It is based on TEIQue long form developed by Petrides and Furnham (K. V. Petrides \& Furnham, 2003). The scale contains 30 items and it is a 7 - point Likert-type (from 1: I completely disagree to 7: I completely agree) scale designed to measure total emotional intelligence trait. It includes the "well-being," "self-control skills", "emotional skills," and "social skills" sub-scales. Criterion-dependent validity of the scale was supported by negative significant correlations with TEIS-SF total score and well-being, self-control skills, emotional skills and social skills sub-dimensions and positive significant correlations with extroversion, openness to experience, amenability and responsibility sub- dimensions (K. V. Petrides, 2010). Validity and reliability study for Turkish was conducted by Deniz, Özer, and Isik (2013) and 4 dimensions of well-being, self-control skills, emotional skills, and social skills were identified. Higher scores correspond to a higher level of emotional intelligence. Reliability coefficients of Trait Emotional Intelligence Scale - Short Form as determined by the analyses conducted by Deniz et al. (2013); K. Petrides and Furnham (2000), and the current study are presented in Table 2 .

Table 2. Reliabilities of Emotional Intelligence Dimensions

\begin{tabular}{|c|c|c|}
\hline Scale & Petrides (2010) studies & Study \\
\hline Well-being & $.74-.80$ & 0.61 \\
\hline Self-control & $.59-.75$ & 0.85 \\
\hline Emotional & $.66-.69$ & 0.64 \\
\hline Social & $.60-.69$ & 0.65 \\
\hline
\end{tabular}

Internal consistency reliability for TEIS-SF was calculated with Cronbach alpha coefficient. These values were $.61, .85, .64, .65$; and .683 for well-being factor, self-control, emotional skills, social skills, and the total scale, respectively.

After the implementation of the questionnaires to the participant students, SPSS 20 software was utilized to analyse the collected data. Pearson Product Moment Correlation Analysis was utilized to determine the relationships between Online Learning Readiness dimensions and Trait Emotional Intelligence dimensions of the students. Finally, Multiple Linear Regression Analysis was conducted to determine the predictive power on online learning readiness dimensions, and standardized regression coefficients, semi-partial correlation coefficients, multiple regression, R2 (determination coefficient), and adjusted R2 (adjusted determination coefficient) values were determined.

\section{Findings}

The number of participants, possible minimum and maximum points, means scores, and standard deviation points for the participating students in Online Learning Readiness and Online Readiness dimensions are presented in Table 3.

The sum of the answers to each item in that dimension was identified and then divided the sum by the number of 
that dimension's items. The higher mean score indicates the higher level of readiness. As it is shown in Table 3, within the limits of the students surveyed, all students' average scores relative to the different dimensions range from 3.105 to 3.667 on a 5-point Likert type rating scale, indicating that students exhibited above-medium levels of readiness for online learning.

Table 3. Descriptive Statistics of Online Learning Readiness Dimensions and Online Learning Readiness

\begin{tabular}{|c|c|c|c|c|c|}
\hline Dimensions & N & Min. & Max. & Mean & Sd. \\
\hline Computer/Internet Self-efficacy & 95 & 1 & 5 & 3,456 & 0,896 \\
\hline Self-directed Learning & 95 & 1 & 5 & 3,640 & 0,674 \\
\hline Learner Control & 95 & 1 & 5 & 3,105 & 0,841 \\
\hline Motivation to Learn & 95 & 1 & 5 & 3,587 & 0,914 \\
\hline Online Communication Self-efficacy & 95 & 1 & 5 & 3,667 & 0,888 \\
\hline
\end{tabular}

The number of participants, possible minimum and maximum points, means scores, and standard deviation points for the participating students in emotional intelligence and emotional intelligence sub-dimensions are presented in Table 4.

Table 4. Descriptive statistics of emotional intelligence dimensions and emotional intelligences

\begin{tabular}{|c|c|c|c|c|c|}
\hline Dimensions & N & Min. & Max. & Mean & Sd \\
\hline Well-being & 95 & 1 & 7 & 4,884 & 1,141 \\
\hline Self-control & 95 & 1 & 7 & 5,058 & 1,197 \\
\hline Emotional & 95 & 1 & 7 & 4,850 & 1,200 \\
\hline Social & 95 & 1 & 7 & 5,034 & 0,640 \\
\hline
\end{tabular}

Each student's mean score for every dimension, the sum of the answers to each item in that dimension was identified and then divided the sum by the number of that dimension's items. The higher mean score indicates the higher level of Emotional Intelligence. As it is shown in Table 4, within the limits of the students surveyed, all students' average scores relative to the different dimensions range from 4.850 to 5.058 on a 7-point Likert type rating scale, indicating that students exhibited above-medium levels of Emotional Intelligence.

Correlation analysis results conducted to determine the relationships between students' online readiness levels and emotional intelligence levels based on the research question "Is there a significant relationship between emotional intelligence levels and online learning readiness levels of the students?" are presented in Table 5.

The data presented in Table 5 demonstrates that there is a significant positive relationship between the trait emotional intelligence level of social skills and online readiness levels of online communication self-efficacy $(\mathrm{r}=.68 ; \mathrm{p} \leq .01)$, motivation to learn $(\mathrm{r}=.73 ; \mathrm{p} \leq .01)$, learner control $(\mathrm{r}=.57 ; \mathrm{p} \leq .01)$, self-directed learning $(\mathrm{r}=.65 ; \mathrm{p}$ $\leq .01)$, and computer/Internet self-efficacy $(\mathrm{r}=.68 ; \mathrm{p} \leq .01)$. Furthermore, there were significant positive relationships between the trait emotional intelligence level of self-control skills and online readiness levels of online communication self-efficacy $(\mathrm{r}=.23 ; \mathrm{p} \leq .05)$, motivation to learn $(\mathrm{r}=.38 ; \mathrm{p} \leq .01)$, learner control $(\mathrm{r}=.97 ; \mathrm{p} \leq .01)$, self-directed learning $(\mathrm{r}=.33 ; \mathrm{p} \leq .01)$, and computer/Internet self-efficacy $(\mathrm{r}=.37 ; \mathrm{p} \leq .01)$. There were also significant positive relationships between the trait emotional intelligence level of well-being and online communication self-efficacy $(\mathrm{r}=.38 ; \mathrm{p} \leq .01)$, motivation to learn $(\mathrm{r}=.44 ; \mathrm{p} \leq .01)$, learner control $(\mathrm{r}=.46 ; \mathrm{p} \leq .01)$, self-directed learning $(\mathrm{r}=.38 ; \mathrm{p} \leq .01)$, and computer/Internet self-efficacy $(r=.30 ; \mathrm{p} \leq .01)$.

Table 5. Correlation matrix between emotional intelligence levels and online learning readiness levels of the students.

\begin{tabular}{|l|c|c|c|c|c|c|c|c|c|}
\hline & 1 & 2 & 3 & 4 & 5 & 6 & 7 & 8 & 9 \\
\hline 1. Online Com. Self-efficacy & 1 & & & & & & & & \\
\hline 2. Motivation to Learn & .53 & 1 & & & & & & & \\
\hline 3. Learner Control & .27 & .42 & 1 & & & & & & \\
\hline 4. Self-directed Learning & .44 & .52 & .37 & 1 & & & & & \\
\hline 5. Comp./Internet Self-efficacy & .45 & .44 & .39 & .61 & 1 & & & & \\
\hline 6. Social Skill & .68 & .73 & .57 & .65 & .68 & 1 & & & \\
\hline 7. Emotional & .02 & .06 & .04 & .18 & .19 & .19 & 1 & & \\
\hline 8. Self-control & .23 & .38 & .97 & .33 & .37 & .52 & .01 & 1 & \\
\hline 9. Well-being & .38 & .44 & .46 & .38 & .30 & .49 & .01 & .46 & 1 \\
\hline
\end{tabular}


Table 6. Regression matrix between emotional intelligence levels and online learning readiness levels of the students.

\begin{tabular}{|c|c|c|c|c|c|c|}
\hline & & 1 & 2 & 3 & 4 & 5 \\
\hline & & $\begin{array}{c}{[\mathrm{R}=.68 ; \mathrm{R} 2=.47]} \\
\mathrm{F}(4-90)=19.68 \\
\mathrm{p}=.00\end{array}$ & $\begin{array}{c}{[\mathrm{R}=.66 ; \mathrm{R} 2=.43]} \\
\mathrm{F}(4-90)=16.98 \\
\mathrm{p}=.00\end{array}$ & $\begin{array}{c}{[\mathrm{R}=.98 ; \mathrm{R} 2=.95]} \\
\mathrm{F}(4-90)=456.44 \\
\mathrm{p}=.00\end{array}$ & $\begin{array}{c}{[\mathrm{R}=.74 ; \mathrm{R} 2=.55]} \\
\mathrm{F}(4-90)=26.97 ; \\
\mathrm{p}=.00\end{array}$ & $\begin{array}{c}{[\mathrm{R}=.71 ; \mathrm{R} 2=.51]} \\
\mathrm{F}(4-90)=22.93 \\
\mathrm{p}=.00\end{array}$ \\
\hline \multirow{3}{*}{ 1.Well-being } & $\beta$ & -.04 & .10 & -.01 & .11 & .11 \\
\hline & $t$ & -.41 & 1.03 & -.47 & 1.25 & 1.23 \\
\hline & $p$ & .68 & .31 & .64 & .22 & .22 \\
\hline \multirow{3}{*}{ 2.Self-control } & $\beta$ & .04 & -.03 & .93 & -.03 & -.21 \\
\hline & $\mathrm{t}$ & .41 & -.29 & 33.43 & -.37 & -2.35 \\
\hline & $\mathrm{p}$ & .68 & .78 & $.00 * *$ & .71 & $.02 *$ \\
\hline \multirow{3}{*}{ 3.Emotional } & $\beta$ & .06 & .07 & .01 & -.07 & -.13 \\
\hline & $\mathrm{t}$ & .76 & .82 & .48 & -.98 & -1.66 \\
\hline & $\mathrm{p}$ & .45 & .42 & .63 & .33 & .10 \\
\hline \multirow{3}{*}{$\begin{array}{l}\text { 4.Social } \\
\text { Skills }\end{array}$} & $\beta$ & .67 & .60 & .09 & .71 & .76 \\
\hline & $t$ & 6.81 & 5.96 & 3.03 & 7.84 & 8.05 \\
\hline & $p$ & $.00 * *$ & $.00 * *$ & $.00 * *$ & $.00 * *$ & $.00 * *$ \\
\hline
\end{tabular}

Regression analysis results concerning the second research question of the study; "Are emotional intelligence levels significant predictors of online learning readiness levels?" are presented in Table 6.

According to the analysis presented in table 6 , there is a moderate level of significant relationship between the students' emotional intelligence levels and online readiness level of computer/Internet self-efficacy $(\mathrm{R}=.68$; $\mathrm{p} \leq .01)$. These predictor variables explained $47 \%$ of the variance in computer/Internet self-efficacy. The relative order of significance of emotional intelligence sub-dimensions on computer/Internet self-efficacy based on standardized regression coefficients were; social skills $(\beta=.67)$, emotional skills $(\beta=.06)$, self-control skills $(\beta$ $=.04)$, and well- being ( $\beta=-.04)$ emotion sub-dimensions, respectively. Assessment of the t-test results on the significance of regression coefficients demonstrated that emotional intelligence sub-dimension social skills $(t=$ $6.81 ; \mathrm{p} \leq .01)$ was a significant predictor of online readiness dimension computer/Internet self-efficacy.

Furthermore, there was a moderate level of significant relationship between the students' emotional intelligence levels and online readiness level of self-directed learning $(\mathrm{R}=.66 ; \mathrm{p} \leq .01)$. These predictor variables explained $43 \%$ of the variance in self-directed learning. The relative order of significance of emotional intelligence sub- dimensions on self-directed learning based on standardized regression coefficients were; social skills $(\beta=.60)$, well-being ( $\beta$ $=.10)$, emotional skills $(\beta=.07)$, and self-control skills $(\beta$ $=-.01$ ) emotion sub-dimensions, respectively. Assessment of the t-test results on the significance of regression coefficients demonstrated that emotional intelligence sub-dimension social skills $(\mathrm{t}=5.96 ; \mathrm{p} \leq .01)$ was a significant predictor of online readiness self-directed learning dimension.
The data presented in Table 6 demonstrated that, in addition to those, there is a very high level of significant relationship between the students' emotional intelligence levels and online readiness level of learner control $(\mathrm{R}=.98$; $\mathrm{p} \leq .01)$. These predictor variables explained $95 \%$ of the variance in learner control. The relative order of significance of emotional intelligence sub-dimensions on learner control based on standardized regression coefficients were; self-control skills $(\beta=.93)$, social skills $(\beta=.90)$, emotional skills $(\beta=.01)$, well -being $(\beta=.01)$ emotion sub-dimensions, respectively. Assessment of the $t$-test results on the significance of regression coefficients demonstrated that emotional intelligence sub-dimension self-control skills $(\mathrm{t}=33.43 ; \mathrm{p} \leq .01)$ and social skills ( $\mathrm{t}$ $=3.03 ; \mathrm{p} \leq .01)$ were significant predictors of online readiness learner control dimension.

Data presented in Table 6 demonstrated that there was a high level of significant relationship between the students' emotional intelligence levels and online readiness level of motivation to learn $(\mathrm{R}=.74 ; \mathrm{p} \leq .01)$. These predictor variables explained $95 \%$ of the variance in motivation to learn. The relative order of significance of emotional intelligence sub-dimensions on motivation to learn based on standardized regression coefficients were; social skills ( $\beta=.71)$, well-being $(\beta=.11)$, emotional skills $(\beta=.07)$, and self-control skills $(\beta=.03)$ emotion sub- dimensions, respectively. Assessment of the t-test results on the significance of regression coefficients demonstrated that emotional intelligence sub-dimension social skills $(t=7.84$; $\mathrm{p} \leq .01)$ was a significant predictor of online readiness motivation to learn dimension.

Based on the student data in Table 6, there was a strong high level of significant relationship between the students' emotional intelligence levels and online readiness level of online communication self-efficacy $(\mathrm{R}=.71 ; \mathrm{p} \leq .01)$. 
These predictor variables explained $51 \%$ of the variance in online communication self-efficacy. The relative order of significance of emotional intelligence sub-dimensions on online communication self-efficacy based on standardized regression coefficients were; social skills $(\beta=.76)$, well-being $(\beta=.11)$, emotional skills $(\beta=.13)$, and self-control skills $(\beta=.21)$ emotion sub-dimensions, respectively. Assessment of the t-test results on the significance of regression coefficients demonstrated that emotional intelligence sub-dimension self-control skills $(\mathrm{t}=-2.35 ; \mathrm{p} \leq .01)$ and social skills $(\mathrm{t}=8.05 ; \mathrm{p} \leq .01)$ were significant predictors of online readiness online communication self-efficacy dimension.

\section{Results, Conclusions and Recommendations}

The present study aimed to scrutinize the relationships between students' online learning readiness and trait emotional intelligence levels. The results of the study confirmed that there was a relationship between students' online learning readiness and trait emotional intelligence levels. Literature review revealed that a study by Berenson, Boyles, and Weaver (2008) investigated whether emotional intelligence affected the achievement in online learning. The results of the above-mentioned study revealed that emotional intelligence was directly effective on the achievement of students, which is compatible with the findings of the current study.

Detailed analysis of the findings of the study would show that there were significant positive relationships between emotional intelligence sub-dimensions social skills, self-control skills, and well-being and online learning readiness sub-dimensions. In other words, as the social skill, self-control skill and well-being levels increase, the tendencies of students to demonstrate the behavior that were considered as a part of online learning readiness increase as well.

Another finding of the study demonstrated that emotional intelligence sub-dimensions predicted $51 \%$ of online learning readiness level online communication self-efficacy and social skills and well-being emotional intelligence sub-dimensions had more predictive power than other emotional intelligence sub-dimensions over online communication self-efficacy. Thus, it could be stated that individuals with high social skill and well-being emotional intelligence levels could have more self-confidence in online communication self-efficacy behavior such as using online tools (e-mail, discussion boards) to communicate with others efficiently, expressing themselves in written communications (emotions and jokes), and asking questions in online discussion environment.

In addition, it was observed that emotional intelligence sub-dimensions predicted $47 \%$ of online learning readiness
computer/Internet self-efficacy level and social skills emotional intelligence sub-dimension had more prediction power on computer/Internet self-efficacy when compared to other emotional intelligence sub-dimensions. Thus, it could be stated that individuals with high social skills could have more self-confidence in computer/Internet selfefficacy behavior such as using basic functions of Microsoft Office Programs (Word, Excel and PowerPoint), how to use online learning software, and using the Internet in the process of accessing information.

It was observed that emotional intelligence sub-dimensions predicted $43 \%$ of online learning readiness self- directed learning level and social skills emotional intelligence sub-dimension had more prediction power on self- directed learning when compared to other emotional intelligence sub-dimensions. Thus, it could be stated that individuals with high social skills could be more successful in self-directed learning behavior such as implementing own study plans, searching for support when learning problems are encountered, good time management, determining own learning targets, and having high expectations for learning performance. Furthermore, it was observed that emotional intelligence sub-dimensions predicted $95 \%$ of online learning readiness learner control level and self-control skills emotional intelligence sub-dimension had more prediction power on learner control when compared to other emotional intelligence sub-dimensions. Thus, it could be stated that individuals with high self-control skills could be more successful in learner control behavior such as directing self-learning process in online environment, keeping own-concentration while online learning despite the existence of other online activities, and repeating online learning material based on needs.

Another finding of the study was the fact that emotional intelligence sub-dimensions predicted $55 \%$ of online learning readiness motivation to learn level and social skills and well-being emotional intelligence sub- dimensions had more prediction power on motivation to learn than other emotional intelligence sub -dimensions. Thus, it could be stated that individuals with high social skills and well-being could be more successful in motivation to learn behavior such as openness to new ideas in online environment, motivation for learning in online environment, learning from own mistakes in online environment, and liking to share own ideas with others in online environment.

Berenson et al. (2008) determined that emotional intelligence was directly related to success in online environment. Hukle (2009) also mentioned that students' readiness improved online learning and in other studies it was reported that learners' online readiness levels was a structure directly related to the achievements of learners in e-learning environments (Artino, 2009; Galy, Downey, \& Johnson, 2011; Kruger-Ross \& Waters, 2013). Parallel to these studies that reported that online learning readiness 
and emotional intelligence separately affected achievements, the present study investigated the relationships between online readiness and emotional intelligence. As a result, it was observed that online learning readiness was related to the individual's emotional intelligence dimensions. It was noted that the online learning readiness levels of the individuals with high emotional intelligence sub- dimension social skills were high as well. Furthermore, it was determined that self-control skills emotional intelligence sub-dimension had more prediction power over online readiness level learner control when compared to other emotional intelligence sub-dimensions. Results of the present study demonstrated that one of the predictors of students' readiness, which is a significant factor in all settings where education is present, was the emotional intelligence levels of individuals in online environments.

\section{REFERENCES}

[1] Artino, A. R. (2009). Online learning: Are subjective perceptions of instructional context related to acad emic success? The Internet and Higher Education, 12(3), 117-125.

[2] Bandura, A., Barbaranelli, C., Caprara, G. V., \& Pastorelli, C. (1996). Multifaceted impact of self-efficacy beliefs on academic functioning. Child development, 1206-1222.

[3] Bar-On, R. (1997). Development of the Bar-On EQ-i: A measure of emotional and social intelligence. Paper presented at the 105th Annual Convention of the American Psychological Association in Chicago.

[4] Berenson, R., Boyles, G., \& Weaver, A. (2008). Emotional intelligence as a predictor of success in online learning. The International Review of Research in Open and Distributed Learning, 9(2).

[5] Bloom, B. (1995). İnsan nitelikleri ve okulda öğrenme. Ankara: Milli Eğitim Basımevi.

[6] Borotis, S., \& Poulymenakou, A. (2004). E-Learning Readiness Components: Key Issues to Consider Before Adopting e-Learning Interventions. Paper presented at the E-Learn: World Conference on E-Learning in Corporate, Government, Healthcare, and Higher Education 2004, Washington, DC, USA. https://www.learntechlib.org/p/11555

[7] Brackett, M. A., Mayer, J. D., \& Warner, R. M. (2004). Emotional intelligence and its relation to everyday behaviour. Personality and Individual Differences, 36(6), 1387-1402. doi:http://dx.doi.org/10.1016/S0191-8869(03)00236-8

[8] Buzdar, M. A., Ali, A., \& Tariq, R. U. H. (2016). Emotional Intelligence as a Determinant of Readiness for Online Learning. The International Review of Research in Open and Distributed Learning, 17(1).

[9] Choucri, N., Maugis, V., Madnick, S., Siegel, M., Gillet, S., O'Donnel, S., Haghseta, F. (2003). Global e - readiness-for what. Center for eBusiness at MIT.

[10] Cooper, R. K., Sawaf, A., Ayman, Z. B., \& Sancar, B. (2003). Liderlikte duygusal zeka: Yönetim ve organizasyonlarda duygusal zeka: Sistem Yayıncılik.

[11] Corbalan, G., Kester, L., \& van Merriënboer, J. J. G. (2009). Combining shared control with variability over surface features: Effects on transfer test performance and task involvement. Computers in Human Behavior, 25(2), 290-298. doi: http://dx.doi.org/10.1016/j.chb.2008.12.009

[12] Davis, T. S. B. (2006). Assessing online readiness: Perceptions of distance learning stakeholders in three Oklahoma community colleges. (Unpublished doctoral dissertation). Oklahoma State University, Stillwater.

[13] De Bruyn, L. L. (2004). Monitoring online communication: can the development of convergence and social presence indicate an interactive learning environment? Distance Education, 25(1), 67-81.

[14] Demir Kaymak, Z., \& Horzum, M. B. (2013). Relationship between Online Learning Readiness and Structure and Interaction of Online Learning Students. Educational Sciences: Theory and Practice, 13(3), 1792-1797.

[15] Deniz, M. E., Özer, E., \& Isik, E. (2013). Trait Emotional Intelligence Questionnaire -Short Form: Validity and reliability studies. Egitim ve Bilim, 38(169).

[16] Flood, J. (2004). NOTE FOR EDITOR: Successful Online Learning-the Five Ps. Turkish Online Journal of Distance Education, 5(2).

[17] Fogerson, D. L. (2005). Readiness factors contributing to participant satisfaction in online higher education courses. (Unpublished doctoral dissertation). The University of Tennessee, Knoxville.

[18] Fraenkel, J. R., \& Wallen, N. E. (2004). How to design and evaluate research in education (4th ed.). New York: McGraw-Hill.

[19] Galy, E., Downey, C., \& Johnson, J. (2011). The effect of using e -learning tools in online and campus-based classrooms on student performance. Journal of Information Technology Education, 10(1), 210-230.

[20] Gunawardena, C. N., \& Duphorne, P. L. (2001). Which Learner Readiness Factors, Online Features, and CMC Related Learning Approaches Are Associated with Learner Satisfaction in Computer Conferences? Paper presented at the American Educational Research Association Annual Meeting.

[21] Hukle, D. R. L. (2009). An evaluation of readiness factors for online education. (Unpublished doctoral dissertation). Mississippi State University, Mississippi.

[22] Hung, M.-L., Chou, C., \& Chen, C.-H. (2010). Learner readiness for online learning: Scale development and student perceptions. Computers \& Education, 55(3), 1080-1090.

[23] Khan, I. M. (2009). An analysis of the motivational factors in online learning. (Unpublished doctoral dissertation). University of Phoenix, Arizona.

[24] Knowles, M. S. (1975). Self-Directed Learning: A Guide for Learners and Teachers. United States of America: 
Cambridge Adult Education.

[25] Kruger-Ross, M. J., \& Waters, R. D. (2013). Predicting online learning success: Applying the situational theory of publics to the virtual classroom. Computers \& Education, 61, 176-184.

[26] Lau, C. Y., \& Shaikh, J. M. (2012). The impacts of personal qualities on online learning readiness at Curtin Sarawak Malaysia (CSM). Educational Research and Reviews, 7(20), 430.

[27] Lawless, K. A., \& Brown, S. W. (1997). Multimedia learning environments: Issues of learner control and navigation. Instructional science, 25(2), 117-131.

[28] Lim, D. H. (2004). Cross cultural differences in online learning motivation. Educational Media International, 41(2), 163-175.

[29] Lin, B., \& Hsieh, C.-t. (2001). Web-based teaching and learner control: A research review. Computers \& Education, 37(3), 377-386.

[30] Mikolajczak, M., \& Luminet, O. (2008). Trait emotional intelligence and the cognitive appraisal of stressful events: An exploratory study. Personality and Individual Differences, 44(7), 1445-1453.

[31] Oh, E. (2006). Current Practices in Blended Instruction. (Unpublished doctoral dissertation). The University of Tennessee, Knoxville.

[32] Palloff, R. M., \& Pratt, K. (2007). Building online learning communities: Effective strategies for the virtual classroom: John Wiley \& Sons

[33] Petrides, K., Frederickson, N., \& Furnham, A. (2004). The role of trait emotional intelligence in academic performance and deviant behavior at school. Personality and Individual Differences, 36(2), 277-293.

[34] Petrides, K., \& Furnham, A. (2000). On the dimensional structure of emotional intelligence. Personality and Individual Differences, 29(2), 313-320.

[35] Petrides, K., \& Furnham, A. (2001). Trait emotional intelligence: Psychometric investigation with reference to established trait taxonomies. European journal of personality, 15(6), 425-448.

[36] Petrides, K. V. (2010). Trait emotional intelligence theory. Industrial and Organizational Psychology, 3(2), 136-139.

[37] Petrides, K. V., \& Furnham, A. (2003). Trait emotional intelligence: Behavioural validation in two studies of emotion recognition and reactivity to mood induction. European journal of personality, 17(1), 39-57.

[38] Polatcan, M., Titrek, O. (2014). The Relationship between Leadership Behaviors of School Principals and their Organizational Cynicism Attitudes. Procedia - Social and Behavioral Sciences, 141, 1291-1303.

[39] Ramo, L. G., Saris, W. E., \& Boyatzis, R. E. (2009). The impact of social and emotional competencies on effectiveness of Spanish executives. The Journal of Management Development, 28(9), 771-793.
[40] Rex, K., \& Roth, R. M. (1998). The relationship of computer experience and computer self-efficacy to performance in introductory computer literacy courses. Journal of research on computing in education, 31(1), 14-24.

[41] Salovey, P., Mayer, J. D., Goldman, S. L., Turvey, C., \& Palfai, T. P. (1995). Emotional attention, clarity, and repair: Exploring emotional intelligence using the Trait Meta-Mood Scale. Emotion, disclosure, and health, 125, 154.

[42] Schulte, M. J., Ree, M. J., \& Carretta, T. R. (2004) Emotional intelligence: Not much more than $\mathrm{g}$ and personality. Personality and Individual Differences, 37(5), 1059-1068.

[43] Shen, D., Cho, M.-H., Tsai, C.-L., \& Marra, R. (2013). Unpacking online learning experiences: Online learning self-efficacy and learning satisfaction. The Internet and Higher Education, 19, 10-17. doi:http://dx.doi.org/10.1016/j.iheduc.2013.04.001

[44] Shyu, H.-Y., \& Brown, S. W. (1992). Learner Control versus Program Control in Interactive Videodisc Instruction: What Are the Effects in Procedural Learning? International Journal of Instructional Media, 19(2), 85-96.

[45] Smith, P. J., Murphy, K. L., \& Mahoney, S. E. (2003). Towards identifying factors underlying readiness for online learning: An exploratory study. Distance Education, 24(1), 57-67.

[46] Spence, G., Oades, L. G., \& Caputi, P. (2004). Trait emotional intelligence and goal self-integration: important predictors of emotional well-being? Personality and Individual Differences, 37(3), 449-461. doi:http://dx.doi.org/10.1016/j.paid.2003.09.001

[47] Stephenson, J. (2001). Teaching and Learning Online: New Pedagogies for New Technologies (Creating Success): Stephenson, J., Kogan Page, London.

[48] Tsai, M.-J., \& Tsai, C.-C. (2003). Information searching strategies in web-based science learning: The role of Internet self-efficacy. Innovations in Education and Teaching International, 40(1), 43-50.

[49] Titrek, O. (2013). IQ'dan EQ'ya: Duyguları Zekice Yönetme, Geliştirilmiş 4. Baskı, Ankara: Pegem Akademi.

[50] Warner, D., Christie, G., \& Choy, S. (1998). Readiness of VET clients for flexible delivery including on-line learning. Brisbane: Australian National Training Authority.

[51] Wong, C.-S., \& Law, K. S. (2002). The effects of leader and follower emotional intelligence on performance and attitude: An exploratory study. The leadership quarterly, 13(3), 243-274.

[52] Yurdugül, H., \& Sarikaya, D. A. (2013). The scale of online learning readiness: A study of validity and reliability. Egitim ve Bilim, 38(169).

[53] Zhoc, K. C. H., \& Chen, G. (2016). Reliability and validity evidence for the Self-Directed Learning Scale (SDLS). Learning and Individual Differences, 49, 245-250. doi:http://dx.doi.org/10.1016/j.lindif.2016.06.013 